Journal of NELTA Gandaki (JoNG), III (1 \& 2), 82-92

ISSN 2676-1041 (Print)

DOI : https://doi.org/10.3126/jong.v3i1-2.33147

\title{
Socio-economic and Psychological Impact of COVID-19 on English Learners
}

Ranjana Kumari Jha

Article History: Received May 26, 2020; Revised August 14, 2020; Accepted October 4, 2020; Online Published November 2020

To cite this article: Jha, R. K. (2020). Socio-economic and psychological impact of COVID-19 on English learners. Journal of NELTA Gandaki (JoNG), III (1\&2), 82-92. DOI : https://doi.org/10.3126/jong.v3i1-2.33147

\begin{abstract}
The COVID-19 crisis has brought up unprecedented and complex issues for us all. COVID-19 crisis has made global impact in most of the sectors, including socio-economic and psychological impacts. Therefore, this study designed to address socio-economic and psychological impacts of COVID-19 on English learners. For this purpose, a sample of 50 students and 4 teachers were selected from two schools following random sampling procedures. Similarly, two key tools for collecting data were used, namely questionnaires and interviews. After analyzing the data collected through the online questionnaire and interview sheet, it has been found that COVID-19 has affected on socio-economic and psychological factors. Most of the students do not always take online class because of lack of money. During COVID-19, students sell fruits on the way. Psychologically, students are weak. So, they try to commit suicide and students do not enjoy online classes because of the lack of creativity in online. Furthermore, almost all the teachers opined that the presences of students are very low in online classes because of poor economic condition. Thus, COVID-19 directly impacts English learners' all aspects of life.
\end{abstract}

Keywords: COVID-19, English learners, socio-economic impacts, psychological impacts

\section{Introduction}

The world health organization [WHO] (2020) announced COVID-19 as a global pandemic on March 11, 2020. The diseases have advanced into a pandemic, started with small chains of spreading, further culminating into larger chains spread in many countries resulting in the widespread transmission consequently across the globe affecting all the continents (Anderson et.al, 2020). COVID - 19 has progressed to affect in many more sectors especially, in socio-economic and psychological. These are highlighted below in terms of thematically.

\section{Socio-economic Impacts of COVID-19 on English Learners}

The economic impact is bi-directional for COVID-19. It has both supply and demand effects. Concerning consumption, we have been facing changing consumer attitudes and marketing channels. At the beginning of the COVID-19 processes, rising consumer demand has been encountered attached to stockpiling. But both the demand dynamics and consumption and purchasing attitudes have changed. Web-based online shopping tools have long been used all over the world. However, due to the 
quarantine enforcements, offline shopping will still destroy labour market dynamics (Ceylan, Ozkan \& Mulazimogullaria, 2020, pp. 821 - 822). Nicola et.al, (2020) research showed the COVID-19 pandemics has sparked fears of an impending economic crisis and recession. Socio-economic impact of COVID-19 social distancing, self-isolation, and travel restrictions have to lead to a reduced workforce across all economic sectors and caused many jobs to be lost. Likely COVID-19 seriously affects the food sector as regarding the food sector. Nicola et. al, (2020) point out "including food distribution and retailing has been put under strain as a result of people panic - buying and stockpiling food. This has led to increased concerns about shortages of food products such as long-life milk, pasta, rice, and tinned vegetables." Nepal, like any other low - income country has big gaps among its citizenry in terms of their socioeconomic and education/ literacy background. The existing system education and the uneven distribution of its resources have often been blamed for the widening gaps between the haves and have not: in the advent of COVID-19 the digital divide and the e-resources will increase the gaps even further by widening the inequalities between the advantaged and disadvantaged children. A few schools and colleges in urban areas have started to run online classes to mitigate the impact on learning. However, running online classes does not seem to be feasible for most rural schools in Nepal. It is estimated that only $56 \%$ people in Nepal have access in the urban and rural areas have created two-tier of inequalities in Nepalese citizenry i.e. between students who live in an urban area and those from a rural area, and between the rich and poor who can barely afford to access the internet (Dawadi, Giri \& Simkhada, 2020, p.4). It reveals that COVID -19 seriously effects socio - economic of English learners. As there is no sources of money due to closeness of business, factory, etc during lockdown.

\section{Psychological Effects of COVID-19 on English Learners}

The spread of the pandemic, the partial lockdown, the disease intensity, week governance in the health care system, insufficient medical facilities, unawareness, and the sharing of misinformation in the mass media has led to people experiencing peer and anxiety (Doza et.al, 2020, para. 1). Serafini, et al. (2020) research showed many psychological problems and important consequences in terms of mental health including stress, anxiety, depression, frustration, uncertainty during COVID-19 outbreaks emerged progressively. Common psychological reactions related to the mass quarantine which was imposed to attenuate the COVID-19 spread are generalized fear and pervasive community anxiety which are typically associated with disease outbreaks and increased with the escalation of new cases together with inadequate anxiety-provoking information which was provided by media. The psychological reactions to COVID-19 pandemic may from a panic behavior or collective hysteria to pervasive feelings of hopelessness and desperation which are associated with negative outcomes including suicidal behavior. Importantly, other health measures may be compromised by abnormally elevated anxiety (para. 7). Yet, weeks of being in isolation, quarantine, and physical trauma create further loneliness and anxiety and issues of a mental health crisis that have been mostly overlooked. At the individual level and the government level, proper risk communication required. Special, attention should be given to combat child and women abuse. Necessary action should be proposed for the post-recovery phase, suicide prevention, and mental health management 
(Duan \& Zhu, 2020; Gunnell et.al, 2020; Mamun et.al, 2020).

This paper presents a study designed to address socio-economic and psychological impact of COVID - 19 on English learners. The following research questions were designed to frame the study;

1. How does socio-economic factor effect on English learners during COVID-19?

11. What are the psychological effects of COVID-19 on English learners?

\section{Review of Literature}

The fear of infection, quarantine, social isolation, and a lack of self - care even leads individuals to face various critical situations in their everyday lives. Haleem et. al, (2020) show that COVID-19 has affected day- to -day life and is slowing down the global economy. They argue that the economic effects of coronavirus include: the slowing of the manufacturing of essential goods, disruption of the supply chain of products, losses in national and international business, poor cash flow in the market, significant slowing down in the revenue growth while the social consequences include the cancellation or postponement of large - scale sports and tournaments, disruption of the celebration of cultural, religious and festive events, undue stress among the population, social distancing with peers and family members, closure of hotels, restaurants and religious places, closure of places for entertainment such as movie and play theatres, sports clubs, gymnasiums, swimming pools and so on. Fornaro and Wolf (2020), using a simple model, show that the coronavirus trigged a negative supply shock. They suggest that drastic policy interventions both monetary and fiscal - might be needed to prevent this negative supply affecting employment and productivity. Wagner (2020) showed that the health crisis transformed into an economic crisis which was amplified through financial channels. Ozili and Arun (2020) find that the increasing number of lockdown days, monetary policy decisions, and international travel restrictions severely affected the level of global economic activities and the closing, opening, lowest and highest stock price of major stock market indices in the world. Also, they observe that the imposed restriction on the internal movement of people and higher fiscal spending had a positive impact on the level of economic activities. Kuckertz et al. (2020) state that the coronavirus (SARS - COV - 2) and the spread of COVID-19 disease in Nigeria led to rapid shut downs in cities and states across the country which severely affected the tourism industry. The lockdown has affected the socio-economic aspects of peoples' lives causing financial loss, health insecurity, and social distancing. Recent evidence suggests that individuals who are quarantined and kept in isolation are significantly distressed because of anxiety, anger, confusion, and post-traumatic stress symptoms (Brooks et al., 2020). Bhat et. al, (2020) rightly point out that "the pandemic resulted in income loss due to job loss or reduced income due to COVID - 19 lockdown gave birth to domestic problems" (p. 44). Dubey et al. (2020) point out that post quarantine psychological effects may include significant socio-economic distress and psychological symptoms due to financial losses (para.3). Chamorro (2018) argues that people from higher strata have more opportunities and access to better education and better services than those in lower strata (p.65). Dawadi, Giri, and Simkhada (2020) point out that many parents have lost their jobs due to the pandemic and their economic crisis has worsened than ever before. Therefore, it is likely that some parents may not be able to afford their children to attend school or university and children may need 
to work to provide economic support to their family.

\section{Psychological Impacts of COVID-19 on English Learners}

Some studies state that prolonged school closures and home confinement might have the negative effects on children's physical and mental health (Brazendale et. al, 2017). "The psychological impact of quarantine is wide-ranging, substantial and can be long-lasting" (Brooks et. al, 2020). Any disaster-related trauma is likely to cause psychological distress in the presence of psychiatric history (Alvarez, et.al, 2005, Cukor et.al 2010). The public at large may also experience boredom, disappointment, and irritability under the isolation measures (Brooks et al., 2020). Buckler et. al, (2020) argue that "the longer schools are closed, the more drop-out occur. More generally, the longer people pause a learning program, the less likely they are to see themselves as learners. It becomes much harder/ logistically and. It has also triggered a wide variety of psychological problems, such as panic disorder, anxiety, and depression (Qiuj et al., 2020). Bhat et al. (2020) point out that fear causes stress and when we have stressed the hormones cortisol and adrenaline increases and they suppress the effectiveness of the immune system. The suppression of the immune system leaves the body vulnerable to disease and infection (p.44). Dubey et al., (2020) point out that the psychological impact of the quarantine can vary from immediate effects like irritability, fear of contracting and spreading infection to family members, anger, confusion, frustration, loneliness, denial, depression insomnia, etc. (para. 3). The fear of infection, quarantine, social isolation, and a lack of self care even leads individuals to suicide. Predictably, any contagious epidemic outbreaks have deleterious effects on individuals and society (Duan \& Zhu, 2020). The accelerating spread of the COVID-19 and its outcomes around the world has led people to fear, panic, concern, and anxiety (Ahorsu et al., 2020).

\section{Theoretical Perspective}

The development of crisis theory as it is today has its roots based in the 1942 fire at the cocoaunt Grove night club located in the Bay Village of Boston. The November 28th fire that lasted approximately 15 minutes took the lives of 492 people (Thomas, 1992). Following this fire, Lindemann began working with the survivors to gain an understanding of their grief reactions to the crisis. It is explained that situations were more likely to become a crisis for those individuals "who because of personality, previous experiences and other factors are especially vulnerable to this stress and whose emotional resources are taxed beyond their usual adaptive resources" (Aguilera, 1998 p. 2). Situational crises are unexpected or accidental whereas developmental crises are associated with moving from one stage of life to another (Slaiku, 1990). Caplan (1964) points out the crisis period into four phases. The first is the rise of tension, unpleasant effect, and disorganization of behavior stemming from the impact of the stimulus and calling forth the habitual problem-solving techniques in an attempt to return to the state of previous equilibrium. Second, a lack of success along with the continuation of stimulus impact exacerbates the state of tension. The third stage is characterized by the tension reaching a point where it mobilizes additional internal and external resources. In the fourth phase, if the problem continues and can neither be solved by need - satisfaction nor avoided through giving up goals or perceptual distortion, the tension mounts beyond a further threshold or its burden increases overtime to a breaking point major disorganization of the individual with drastic results then occurs. Birdsall et. al, (2004) advocate for holding government accountable for fulfilling their responsibilities toward children during times of crisis, ensuring that they can exercise their 
right to education. Education services delivered during these times and under these conditions are meant to support simultaneously children's cognitive and emotional development while including additional educational content relevant to the crisis circumstances (Burde \& Spring, 2004). Bensalah et al. (2000) points out a key recommendation is that education in emergencies is seen and planned from day one, as part of the development process and not solely as a relief effort. Donors should avoid compartmentalization of funding that can have the effect of creating an uneducated and bitter revenge oriented generation because education in emergencies was seen as the last call on inadequate 'humanitarian budgets (Bensalah et al. 2000). Rapoport (1970) argues that three interrelated factors usually produce a state of crisis: a hazardous event, a threat to life goals, and the inability to respond with adequate coping mechanisms. Jacobson (1968) argues that social, intrapsychic, and somatic components of a crisis. The social aspects of the crisis include any role changes or other alterations in the interpersonal behavior that occur during a crisis the intrapsychic factors of the crisis emphasize the changes in conscious and unconscious processes brought about by crisis, while the somatic aspects of the crisis refer to a somatic illness that might develop as a result of the crisis. Shulberg and Sheldon (1968) have developed a probability formula for a crisis: the probability of a crisis occurring because of a hazardous event is a function of the interaction between the hazardous event, the exposure of the individual to the event, and the vulnerability of the individual. Langsley and Kaplan (1968) suggest that an oriented model which takes into account the social field in which the person deals with the crisis. It is based on the belief that not only the development but also the outcome of the crisis depends in part on the social field of the person in crisis and therefore emphasizes the systems approach to intervention. Parad and Caplan (1960) have noted a crisis is usually also experienced to some extent by the family and social network of the referred person. Therefore, it becomes very important to involve the family and the community in the treatment process as soon as possible, to facilitate not only the resolution of the crisis but also the post-crisis adaptation of the individual. Hafer and Peterson (1982) point out that crisis intervention as the kind of psychological first aid that enables to help an individual or group experiencing a temporary loss of ability to cope with a problem or situation. Shifman (personal communication, 2004) and UNICEF, (2004) reported that economic circumstances push parents and children to take drastic measures such as employing children in economic activity or selling children into various forms of bonded labor.

\section{Methodology}

This is a survey research which included primary as well as secondary sources of data. The population of the study consisted altogether 50 students of grade 10 of two government schools of Parsa district, Birgunj. 50 Students ( 25 from each school) and four language teachers ( 2 from each) were selected for interview. The two government schools of Parsa district were selected through a purposive non-random sampling procedure. The main tools for the collection of data were a set of questionnaires and interview schedules. Data was collected through online.

The headmasters of chosen two government schools were called to build rapport with them and explained the aim of the study. Students were sent questionnaires through email with the help of subject teachers who were teaching students through online. After finishing the questionnaire within a fixed time, students were asked to submit a questionnaire with responses to the researcher. Four language teachers from selected schools were interviewed virtually.

\section{Results and Discussion}


Data collection processes were conducted to ensure that the informants expressed their viewpoints freely and thoroughly. Data were analyzed by using a numerical system and textual method in which the interviews were transcribed, coded, and categorized for understanding the phenomenon in question. Finally, data were analyzed, interpreted, and presented into three different themes in this study.

\section{Socio-economic Impacts of COVID-19 on English Learners}

Regarding COVID-19 socio-economic impact on English learners, Table 1 shows students responses about COVID-19 socio-economic effects on English learners.

Table 1

Socio-economic Impacts of COVID-19 on English Learners

\begin{tabular}{lllllll}
\hline Questions & Total & Strongly Agree (\%) & Agree (\%) & $\begin{array}{l}\text { Strongly } \\
\text { Disagree (\%) }\end{array}$ & Disagree (\%) & Total \\
\hline Question 1 & 50 & $54 \%$ & $46 \%$ & $0 \%$ & $0 \%$ & $100 \%$ \\
Question 2 & 50 & $52 \%$ & $48 \%$ & $0 \%$ & $0 \%$ & $100 \%$ \\
Question 3 & 50 & $36 \%$ & $30 \%$ & $0 \%$ & $34 \%$ & $100 \%$ \\
Question 4 & 50 & $64 \%$ & $36 \%$ & $0 \%$ & $0 \%$ & $100 \%$ \\
Question 5 & 50 & $38 \%$ & $44 \%$ & $0 \%$ & $18 \%$ & $100 \%$ \\
\hline
\end{tabular}

Table 1 shows that students view very significantly about socio-economic effects of COVID 19. Regarding the impacts of socio-economic of COVID-19, 54\% of learners strongly agreed that they do not take always online classes due to a lack of money. And only $46 \%$ of learners agreed to the idea. No one responded in favor of strongly disagree and disagree out of $100 \%$. In the same case, $52 \%$ of learners strongly agreed that they do not enjoy themselves with their friends because of COVID-19. 48\% of learners agreed about it. No one responded in favor of strongly disagree or disagree out of $100 \% .36 \%$ of learners strongly agreed that they sell fruits on the way because of losing their father's job. And 30\% only agreed to the idea. Next $34 \%$ of learners were disagreement out of $100 \%$. $64 \%$ of learners strongly agreed about their parents push them to do housework. And $36 \%$ of only learners agreed to the idea. No one responded in the support of strongly disagree and disagree out of $100 \% .44 \%$ of learners agreed about their parents' force to help them to maintain hands and mouth problems and $38 \%$ only strongly agree about it. Next $18 \%$ of learners were disagreement out of $100 \%$. All the teachers reported that socio-economic effect of COVID-19 is more serious. For example, T1 "Due to COVID-19, most of business office, company and factory have closed. So there is no source of money during COVID - 19. They feel difficult to maintain hands and mouth problems, then how learners can bear net packs for online classes. Most of the learners are dull. They do not know how to face COVID-19. More learners see more scarcity of family so they motivated towards bad activities. Learners do not enjoy with their friends so their speaking skill is not good lack of exposure." In the same context, another informant T2 added:

I think COVID-19 directly affects socio-economic sector more. As I see in my community, many good learners compel to sell fruits, vegetables on the way because of losing their father's job. Some parents push them to do housework. Some learners are not getting mobile for study so they are doing 
suicide. Some learners motivated towards social evils activities by watching scarcity of family.

These accounts above reveal that COVID-19 seriously effects socio-economic of English learners. As there are no sources of money due to closeness of business, factory, etc. during COVID-19, many learners do not take online classes. Learners faced many more scarcities so they divert towards social evils activities. Due to the long gaping of learning, learners are dull. Due to lack of friends circle, learner's speaking skills and communicative skills are poor. Many good learners have a compulsion to sell fruits, vegetables on the way because of losing their father's job. Some parents force them to do housework. Some learners cannot tolerate scarcity so they do suicide. Due to parents' force, they involve to solve hands and mouth problems by leaving the study. In this context T4 shared:

I feel socio-economic effect of COVID-19 are more prominent. As our whole life is based on socioeconomic, COVID-19 affects in every sector including food, sports industry, the housing sector, travel industry, finance industry, manufacturing industry petroleum and oil agriculture, domestic violence, and home video-gaming, etc.

The accounts above reflect that the participants expressed their experiences of socio-economic effects of COVID-19. Learners are buying high expensive food due to lockdown and curfew. Earning income has stopped so different socio-problems have created like a quarrel in-home, domestic violence, most learners pass their time by playing video-game. Especially, the agriculture sector is badly affected. Most farmers' production has destroyed due to COVID-19. Most people are hardly managing hands and mouth problems. Most of the learners involved in farming and working as labour to short out the economic problems of the family. Higher status learners get more opportunities for learning so, they are good. Whereas, poor status learners get less opportunity for learning so they are not good.

\section{Psychological Impacts of COVID-19 on English Learners}

There are many psychological problems and important consequences in terms of mental health including stress, anxiety, depression, frustration and uncertainty during COVID-19 outbreaks emerged progressively. Table 2 reveals the learners conceptualizations about psychological effects of COVID-19 on English learners.

Table 2

Psychological impacts of COVID-19 on English Learners

\begin{tabular}{lllllll}
\hline Questions & Total & Strongly Agree (\%) & Agree (\%) & $\begin{array}{l}\text { Strongly } \\
\text { Disagree (\%) }\end{array}$ & Disagree (\%) & Total \\
\hline Question 1 & 50 & $90 \%$ & $10 \%$ & $0 \%$ & $0 \%$ & $100 \%$ \\
Question 2 & 50 & $56 \%$ & $44 \%$ & $0 \%$ & $0 \%$ & $100 \%$ \\
Question 3 & 50 & $56 \%$ & $30 \%$ & $0 \%$ & $14 \%$ & $100 \%$ \\
Question 4 & 50 & $54 \%$ & $32 \%$ & $0 \%$ & $14 \%$ & $100 \%$ \\
Question 5 & 50 & $56 \%$ & $44 \%$ & $0 \%$ & $0 \%$ & $100 \%$ \\
\hline
\end{tabular}

In table 2, 90\% of learners were strongly agreed about their fear with COVID-19 because of no vaccine whereas, $10 \%$ of learners were only agreement out of $100 \%$. No one responded in support of 
strongly disagree and disagree about it. $56 \%$ of learners responded strongly agree about learners are more worry by watching increasing numbers of victim persons of coronavirus. And $44 \%$ of learners agreed to the idea out of $100 \%$. No one responded in favor of strongly disagree and disagree about it. $56 \%$ of learners strongly agreed about they think more about the victim of coronavirus. $30 \%$ of learners were agreement whereas only $14 \%$ of learners were disagreement out of $100 \% .54 \%$ of learners showed strongly agree about they like to live alone and talk themselves. And 32\% learners of agreed the idea. Next, only $14 \%$ of learners were disagreement out of $100 \% .56 \%$ of learners strongly agreed that their fear habits increase day by day due to COVID-19. $44 \%$ of learners agreed to the idea. No one responded in favor of strongly disagree and disagree out of $100 \%$. In this connection, T3 stated that "I think COVID-19 will kill people physically as well as mentally. Due to COVID-19, most of the learners are frustrated, depress, and stress about their time and life. COVID-19 increases anxiety, hypertension in people, their fear habit develop day by day. Due to social distance and isolation learners are monotonous": In the same context informant T2 added:

I see in my community most of the learners are in hypertension and fear with COVID-19. When my son saw coronavirus victim person numbers in news then he asked with me that father coronavirus will kill me too. Then I convince him very hardly by saying maintenance of it. Though, he is not cool. I handle my son very carefully. So, I feel that if we feel very difficult to handle this situation then what about other uneducated families? As we know the child's mind is "tabula rasa" i.e. blank sheet of paper.

These accounts above reveal that participants are passing very hard days of COVID-19. Most learners are hypertension as they create problems at home. As a result, they are upset, anxious about their time and life. They think that this year is losing year. By watching the news, and community, they fear with COVID-19 victim person as there is no vaccine. So fear is increasing day by day. Learners are not with their friends so they do not get a chance to share feelings and learn from friends so they feel alone in some cases and they are monotonous. As a participant stated that the child's mind is a blank sheet of paper. Whatever we write at first they store in mind for a long time and it affects very badly in a creative mind.

As today's world is the social networking world. People are updating quickly about COVID -19 by watching the critical situation of other countries. They fear more because our country can't manage like other country management of government is very poor. COVID-19 creates conflict in our society in terms of the distribution of food (rahat bitaran). As a result, learners think more about this case and mentally they become sick. In some cases, I see some learners are talking themselves and fear with even small matters too. They are mentally weeks and they try to commit suicide. The suicide rate is increasing day by day due to COVID-19 in our society (T1).

The accounts above reflect that the conditions of learners are not good. Mentally, they are very week. They see coronavirus victim person increasing numbers and they fear more with COVID - 19. In terms of rahat bitran, they create conflict and provide more distribution to powerful people not to the needy person by watching this situation, mentally they are weak. Most learners are talking themselves due to psychological problems. Learner's fear habits develop day by day due to COVID-19. Parents don't care about their children properly as a result, psychological problems are increasing day by day with learners 
and they decide on suicide.

\section{Conclusion and Implications}

This study was designed to address socio-economic and psychological impacts of COVID-19 on English learners. This study shows that COVID-19 has affected all aspects of human life. Importantly, it affects in socio-economic and psychological sector, socio-economic effects show that students do not take online classes because of a lack of money. Students' parents feel difficult to maintain their hands and mouth due to COVID-19. It is not possible to maintain internet facilities in this crisis. Four language skills have not developed equally due to untrained teachers as the online classes are the only way to conduct classes during COVID-19. They think about victim person more and talk themselves so students do not do creative work psychologically; students are very weak because of no vaccine of COVID - 19. Social distance has become a curse for students as result their English fluency, speaking confidence and communicative skills are not good. Moreover, students do not do creative work so their creative power has not developed during COVID-19.

Furthermore, teachers should be creative to use online different activities for good development of language skills. Teachers should use effective methods for making online classes effective, innovative. In this, critical situation teachers should teach practical knowledge to face COVID-19 easily in English. It helps to make online classes effective and well development of the English language as well as provide proper online training to teachers. COVID-19 related life knowledge in English is the demand of current time.

Socio-economic effects show that learners have the compulsion to sell fruits on the way and parents force them to do housework to maintain hands and mouth problems. Furthermore, the teacher reported that online classes are not good in our context. It creates inequality in education. Therefore, concerning people and institutes should have considerations about the disadvantaged group. If possible then provide free mobile, laptop, and internet facilities to be needed learners. Likewise, the government should make good COVID-19 policies for all. Local government should care more about COVID-19 and apply all maintenance of COVID-19. If possible, the government should prohibit children to sell anything on the way and take action for it, provide more facilities to children. Parents should deal with their children carefully in this situation. Do not leave children alone, be alert about their behavior, provides applicable knowledge to a child for facing COVID-19 easily. Spend more time with children and make them more engaged in creative work. So, they don't commit suicide.

Although the study contributes to getting more knowledge about the effects of COVID-19 as socioeconomic effects and psychological effects which is more demand of current time and more fruitful for the future, this study has many delimitations. First, it was a small-scale survey research including socioeconomics effects and psychological effects; therefore, its findings may have limited applicability. A large scale incorporating multiple layers of participants such as policymakers, administrator teachers, students, and all other concerned stakeholders is needed to take positive action about COVID-19. Nonetheless, it is hoped that this study raises awareness and provides feedback to local and central policymakers, 
governments and concerning stakeholders on various affective aspects of COVID-19.

\section{References}

Aguilera, D. (1998). crisis intervention theory methodology ( $8^{\text {th }}$ ed.). Mosby: St. Louise Mosby.

Alvarez, F.E., Argente, D. \& Lippi, F. (2020, 18 April). A simple planning problem for COVID - 19 Lockdown. NBER working paper series number: 26981. Retrieved from https:/www.nber.org/ paper/w26981

Anderson, R.M. Heesterbeek, H., Klinkenberg, D., \& Hollingsworthd, T. D. (2020). How will country - based mitigation measures in influence the course of the COVID - 19 epidemic? Lancel, 395 (10228), 931-934

Bensalah, K. (2000) Education in situations of emergency and crisis: challenges for the new century. World education forum: for all 200 assessments. Paris: UNESCO

Bhat, B.A., Khan, S., Manzoor, S., Niyaz, A., Tak, H. J., Anees, S. U. M., Gull, S. \& Ahmad, I. (2020). A study on impact of COVID - 19 Lockdown on psychological health economy and social life of people in Kashmir. Retrieved from https://www.ijshr.com.

Birdsal, N. (2004, December 12). Task force 3: Interim report on primary education. Retrieved from https://www.unmillenniumproject.org/documents/tf3edinterim.pdf.

Brooks, S. K., Webster, R. K., Smith, L. E., Woodland, L., Wessely, S., Greenberg, N. \& Rubin, G. J. (2019) The psychological impact of quarantine and how to reduce it: rapid review of the evidence. Lancet 395, 912-920. Retrieved from 10.1016/S0140-736(20)30460-8.

Buckler, A. Chamberlain, L. \& Stutchbury, K. \& Hedge, C. (2020). Minimising distance in distance learning program during a global crisis: framing an international education response to COVID - 19 UKFIET. Retrieved from https:/www.UKFIET.org/2020/minimising distance - i-distance-learningprogram-during-a-global-health-crisis-framing-an-international-education-response-to-COVID-19/

Burde, D. \& Spring, S. ( 2004). Weak states strong communities? Promoting community participation in post - conflict countries. Current issues in Comparative Education Online Journal Teachers College Columbia University. Retrieved from www.tc.columbia.edu/cice

Caplan, G. (1964). Principles Of preventive psychiatry. New York:INC

Ceylan, R. F., Ozkan, B. \& Mulazi M., E. (2020). Historical evidence for economic effects of COVID - 19. the European Journal of Health Economics 21, 817-823. Retrieved from https://doi.org/10.1007/ s10198-020-01206-8

Chamorro, M. (2018). Comparing online English language learning and face to face English language learning at EL. Retrieved from https://scholarscompass.VCU.edu/etd/5343

Dawadi, S., Giri, R. A, \& Simkhada, P. (2020). Impact of COVID - 19 on the education sectors in Nepal: challenges and coping strategies. DOI: 10.3112/advance.12344336.VI

Doza, B. et al. (2020). Psychosocial and socio - economic Crisis in Bangladesh due to COVID - 19 pandemic: A Perception - Based Assessment. Retrieved from https://doi.org/10.3389/fpubh.2020.00341.

Duan L. \& Zhu, G. (2020). psychological interventions for people affected by the COVID - 19 epidemic Lancet psycho; 7(4) 300-302. 
Dubey, S., Biswas, P., Ghosh, R., Chatterjee, S., Dubey, M. J., Chatterjee, S., Lahiri, D. \& Lavieh, C. J. (2020). Psychosocial impact of COVID - 19. Retrieved from www.ncbi.nlm.nih.gov

Fernandes, N.(2020), "Economic effects of corona virus outbreak (COVID- 19) on the world economy", Retrieved from SSRN3557504.

Gunnell, D. \& Appleby, L. (2020) suicide risk and prevention during the COVID -19 pandemic Lancet psycho;

Hopman, J. \& Allegranzi, B. (2020). Managing COVID - 19 in low and middle income countries JAMA. Kuckertz, A., Brändle, L., Gaudig, A., Hinderer, S., Reyes, A. C. M., Prochotta, A., Steinbrink, K. M., \& Berger, E. S. C. (2020). Startups in times of crises - a rapid response to the COVID - 19 pandemic, Journal of Business Venturing Insights, 13, 1-13

Mamun, M. A. \& Siddique A. B. (2020). Students suicide risk and gender: a retrospective study from Bangladeshi Press reports. Int.J.ment. Health Addiction (2020) G.S.

Ozili, P. K. \& Arun, T. (2020). Spillover of COVID - 19: impact on the global economy, Retrieved from SSRN 3562570.

Parad, H. J. \& Caplan, G (1960), The framework for studying families in crisis. Social Work 5(3), 3-15

Qiu. J., Shen, B., Zhao, M., Wang, Z., Xie, B. \& Xu, Y., (2020), A nationwide survey of psychological distress among Chinese people in the COVID - 19 epidemic: implications and policy recommendations. Gen Psychiatr,33

Rapoport, L. (1970). The state of crisis: some theoretical considerations. Social Service Review 36(2), 211-217.

Serafimi, G., Parmigiani, B., Amerio, A., Aguglia, A., Sher, L. \& Amore, M. (2020). The psychological impact of COVID - 19 on the mental health in the general publication. retrieved from https://doi. org//10.1039/qjmed/hcaa20/

Shulberge, H. C. \& Sheldon, A. (1968), The probability of crisis and strategies for preventive intervention. Archives of General Psychiatry 18 (5), 553-558

Slaiku, K. (1990). Crisis intervention: A handbook for practice and research (2 ${ }^{\text {nd }}$ ed.). Boston: Allyn and Bacon. Thomas, J. (1992). The cocoanut grove inferno. The Baston Globe. Retrieved from http://www.boston.com/ new/daily/21/archives-cocoanut-112292.html

UNICEF, (2004) State of the world's children 2005. New York: UNICEF

WHO, (2020, 30 March). Corona disease 2019/COVID - 19 situation Report 51. Retrieved from https:// www.who.int/docs/default-sources/coronaviruse/situation-reports/202000311-sitrep-51-COVID

Ranjana Kumari Jha is a Lecturer of English Education at Tribhuvan University, Nepal. To her credit, about three dozens of articles have been published in different national and international journals. She has also published books, edited journals and presented papers in various conferences and facilitated different training sessions in English Language teaching. Her areas of interests include applied linguistics, research on SLA and English Language curricula, translation studies, Teacher professional development and ICTs in language education. 